\title{
Economic burden of stroke
}

\author{
Afitap İçağasıoğlu, ${ }_{1}^{1}$ Hatice Şule Baklacıoğlu, ${ }^{2}$ Erkan Mesci, ${ }^{1}$ Yasemin Yumuşakhuylu, ${ }^{1}$ Sadiye Murat, ${ }^{1}$ Nilgün Mesci ${ }^{3}$ \\ ${ }^{1}$ Department of Physical Therapy and Rehabilitation, İstanbul Medeniyet University, Göztepe Education and Research Hospital, İstanbul, Turkey \\ ${ }^{2}$ Department of Physical Therapy and Rehabilitation, Bakırköy Mazhar Osman Mental Health and Neurological Diseases Training and Research Hospital, Physical, İstanbul, Turkey \\ ${ }^{3}$ Department of Physical Therapy and Rehabilitation, Haydarpaşa Numune Training and Research Hospital, İstanbul, Turkey
}

Received: February 2016 Accepted: May 2016

\begin{abstract}
Objectives: This study aims to estimate the annual economic cost per hemiplegic patient in Turkey.

Patients and methods: Between September 2014 and December 2014, a total of 84 hemiplegic patients (53 males, 31 females; mean age $61.4 \pm 13.5$ years; range $28-89$ years) with stroke for 12 months were included in the study. Type of cerebrovascular accident and complications were evaluated. Hospital records and data from the relatives of the patients were used to calculate the cost. Annual costs were evaluated starting from first hospitalization. Direct costs were calculated with the sum of hospital care (acute care, diagnostic investigations, treatment and rehabilitation), medications, medical visits, outpatient rehabilitation and orthopedic aids. Indirect costs were calculated by taking the income loss due to absence from work into consideration. Prices of medical resources were obtained from the 2014 Healthcare Implementation Notification payment list.
\end{abstract}

Results: At the end of the study, the average direct cost and indirect cost per patient were calculated respectively as $10,594.90 \pm 6,554.20$ Turkish liras and 9,357.10 $\pm 10,195.60$ Turkish liras (4,606.47 $\pm 2,849.65$ USD and 4,068.30 $\pm 4,432.86$ USD). We found a negative correlation between total cost and age $(\mathrm{p}=0.001)$, and a positive correlation with duration of hospitalization $(\mathrm{p}=0.001)$ and number of complications $(\mathrm{p}=0.049)$. We were unable to find any relation of cost with sex and cerebrovascular accident type. Spasticity $(\mathrm{p}=0.028)$ and epilepsy $(\mathrm{p}=0.037)$ being among the complications were observed to increase the cost.

Conclusion: Stroke is an important economic burden for Turkish population. Preventive social measures are necessary to reduce this cost.

Keywords: Cost of illness; economics; stroke.

Stroke is the major cause of disability and the second most common cause of mortality and a costly disease. ${ }^{[1-3]}$ The economic aspects of stroke are evaluated through a cost-of-illness (COI) studies. Stroke is a global epidemic and by no way a problem limited to western or high-income countries. ${ }^{[4]}$ Cerebrovascular diseases are the second most common cause of death in Turkey. Based on disability adjusted life year (DALY) estimations, cerebrovascular diseases rank third among 10 diseases that account for the total disease burden in Turkey. ${ }^{[5]}$ Ten-year risk of stroke was estimated at $17 \%$ in our country in a study involving 39 centers. ${ }^{[6]}$ Given that old age is a real risk factor for stroke, the increased aging of the world population means a growing number of persons are at risk. ${ }^{[2]}$ Increased incidence of stroke and decreased morbidity owing to newer therapies resulted in an increase in the prevalence of stroke. ${ }^{[7]}$ A substantial number of stroke survivors are left with physical or cognitive impairment and require care. In addition to the direct costs of hospitalization, emergency care, rehabilitation and cost of illness, indirect costs related to the loss of productivity and long-term care further increase the overall cost of stroke. ${ }^{[2]}$

A review on the costs of stroke showed that the expenditures for stroke accounted for about 3\% of total health care expenditures in eight countries. This means that on overage, $0.27 \%$ of the gross national product was spent on stroke. ${ }^{[4]}$ Concerning the cost of stroke in Turkey, only one study is available which evaluated the cost of treatment for patients staying in a rehabilitation center ${ }^{[8]}$ Data on disease costs can be a helpful guide while planning and budgeting healthcare expenditures. In the present study, our purpose was to

Corresponding author: Erkan Mesci, MD. Medeniyet Üniversitesi Göztepe Ĕ̈itim ve Araştırma Hastanesi, Fizik Tedavi ve Rehabilitasyon Kliniği, 34722 Göztepe, Kadıköy, İstanbul, Turkey. e-mail: erkanmesci@hotmail.com 
obtain national data on estimated cost of hemiplegia per patient and draw attention to the economic aspect of hemiplegia in Turkey.

\section{PATIENTS AND METHODS}

The study was conducted on patients with a history of hemiplegia for at least one year who were being followed at Physical Therapy and Rehabilitation outpatient clinics of three state hospitals in Istanbul. Data for hemiplegic patients retrieved from hospital registers and information obtained from patients and their relatives were included in the analysis. Concomitant illnesses and disease related complications, medications and devices used by patients and expenditures of rehabilitation were recorded.

Cost of illness studies were conducted using two methods: (i) Top-down method: This method calculates the national costs of a disease using data banks such as those provided by the National Office of Statistics. (ii) Bottom-up method: A group of patients with a certain disease were asked what the costs of their disease were. ${ }^{[4]}$ The results of this questionnaire are extrapolated to a population level. In the present study, we conducted a cost analysis with the bottomup method using hospital registers and information obtained from stroke survivors.

\section{Cost analysis (Direct and indirect costs)}

Cost-of-illness studies generally involve two separate cost analyses including direct costs and indirect costs. Direct costs refer to all the goods, services and other resources that are consumed during the provision of a health intervention for a certain illness. This includes the money spent on hospital and nursing home care, on the services of physicians and other medical professionals, drugs, appliances and rehabilitation. Indirect costs are defined as production losses due to an illness. They represent the monetary value of the production losses due to absenteeism of the patient and his/her caregiver.

\section{Patient selection}

Patients 18 years of age and older following a diagnosis of hemorrhagic or ischemic stroke were included in the analysis. Demographic characteristics (age, sex, type of stroke) and stroke-related complications (eg. spasticity, aphasia, epilepsy and depression) were collected. Data on cost items were collected using the bottomup method. For direct cost estimation, the duration of stay (number of days) in the neurological acute care unit and the fees for all kinds of investigations, drug administrations, procedures, physician visits, consultations and inpatient rehabilitation services until the time of discharge were retrieved from the computerized hospital databases. Data and information on investigations, medicines administered, appliances, physician visits and outpatient rehabilitation services after discharge were obtained from the patients and their relatives. The unit prices of healthcare resources were obtained from the payment list of 2014 Healthcare Implementation Notification (HIN $)^{[9]}$ and vademecum (a book for ready reference). ${ }^{[10]}$ For indirect costs, annual financial loss was calculated by multiplying the monthly income of the patient by 12 which corresponded to economic losses due to absenteeism. Since most caregivers were unemployed relatives of the patients, potential indirect costs incurred by their loss of productivity were not included in the cost analysis. Approval for the conduct of the study was obtained from the local ethics committee of Istanbul Medeniyet University Goztepe Education and Research Hospital. Informed consent was obtained from patients or their relatives before initiation of the study. The study was conducted in accordance with the principles of the Declaration of Helsinki.

\section{Statistical analysis}

NCSS (Number Cruncher Statistical System), 2007 \& PASS (Power Analysis and Sample Size) and 2008 Statistical Software (Utah, USA) were used for statistical analysis. Descriptive statistical methods (mean, standard deviation, median, frequency, percentage and minimum-maximum) were used for analysis of study data. For between-group comparisons, Student's t-test was used to compare normally distributed quantitative variables and Mann-Whitney $U$ test for non-normally distributed quantitative variables. Spearman's correlation analysis were used to assess relationships between study parameters. A $p$ value of $<0.05$ was considered statistically significant.

\section{RESULTS}

Eighty-four stroke survivors were evaluated in the study: 53 males (63.1\%) and 31 females (36.9\%). The mean age of patients was $61.4 \pm 13.5$ years with an age range of 28-89 years. The type of cerebrovascular accident (CVA) was ischemic in $88.1 \%(n=74)$ of the patients and hemorrhagic in $11.9 \%(n=10)$. The characteristics of stroke patients are shown in Table 1. The length of hospital stay of study patients ranged between 0 and 75 days with a mean duration of $15.4 \pm 11.2$ days. It was found that $61.9 \%(n=52)$ of 
Table 1. Characteristics of patients

\begin{tabular}{|c|c|c|c|c|}
\hline & $\mathrm{n}$ & $\%$ & Mean \pm SD & Min-Max \\
\hline Age (year) & & & $61.4 \pm 13.5$ & $28-89$ \\
\hline Number of stroke & & & $1.4 \pm 0.8$ & $1-5$ \\
\hline Number of comorbidity & & & $2.2 \pm 1.3$ & $0-6$ \\
\hline Number of complications & & & $1.8 \pm 0.8$ & $1-4$ \\
\hline Number of BoNT injections & & & $2.3 \pm 2.0$ & $1-7$ \\
\hline Length of hospitalization stay (day) & & & $15.4 \pm 11.2$ & $0-75$ \\
\hline \multicolumn{5}{|l|}{ Sex } \\
\hline Male & 53 & 63.1 & & \\
\hline Female & 31 & 36.9 & & \\
\hline \multicolumn{5}{|l|}{ Type of stroke } \\
\hline Ischemic & 74 & 88.1 & & \\
\hline Hemorrhagic & 10 & 11.9 & & \\
\hline Spasticity & 52 & 61.9 & & \\
\hline Aphasia & 37 & 44.0 & & \\
\hline Depression & 16 & 19.0 & & \\
\hline Epilepsy & 9 & 10.7 & & \\
\hline Botulinum neurotoxin & 10 & 11.9 & & \\
\hline Rehabilitation & 43 & 51.2 & & \\
\hline
\end{tabular}

SD: Standard deviation; Min: Minimum; Max: Maximum.

stroke survivors had spasticity, 44\% $(\mathrm{n}=37)$ had aphasia, 19\% $(n=16)$ had depression and $10.7 \%(n=9)$ had epilepsy. Botulinum toxins were administered by injection to 10 patients (11.9\%). 51.2\% of the patients $(n=43)$ were enrolled in a rehabilitation program. Thrombolytic therapy was given to only two patients.

Estimated direct cost per person was 10.594,90 $\pm 6.554,20$ (median 8.668,50) Turkish Liras (TL). Costs incurred through hospitalization in neurological care units accounted for the majority of direct costs (acute cost), followed by physical therapy and rehabilitation services. Distribution of costs is presented in Table 2.

Indirect cost of lost productivity from stroke was estimated at 9.357,10 $\pm 10.195,60$ (median 10.800) TL per person. Estimated total annual cost of stroke per person was 19.952 \pm 13.131 (median 17.253,50) TL on average (Table 2).

Based on our findings, there was a significant negative correlation between age and total cost $(\mathrm{r}=0.640, \mathrm{p}=0.001)$. Total cost was not associated with sex, type of CVA or presence of aphasia or depression (all $\mathrm{p}>0.05$ ). Of the study patients, total costs were statistically significantly greater for spastic patients, those who had botulinum toxin injection, epileptic patients and those who received physical therapy and rehabilitation services (Table 3 ).

\section{DISCUSSION}

This study is the first to report total estimated annual cost of stroke per patient in Turkey. Several studies demonstrate that stroke poses a significant burden on society in all developed countries..$^{[2-4,11,12]}$ Despite the use of different methodologies, selected cost-of-illness studies have shown that about $3 \%$ of health care costs were spent on stroke patients. ${ }^{[4]}$ However, costs per capita spent on stroke are more diverse. This can be explained by the relative increase in expenditures on health care costs over time in several developed countries. An alternative explanation might be the difference in data collecting and calculating methods between several COI studies. ${ }^{[4]}$ Also, the costs of stroke may vary depending on the characteristics of patients (type and severity of stroke $)^{[13,14]}$ or the organization of the healthcare system (delivering prolonged acute care versus inpatient rehabilitation services). ${ }^{[4]}$

Cost-of-illness studies, if performed using the top-down model, are based largely on secondary data. Consequently, the estimation of the stroke costs

Table 2. Distribution of the costs of stroke

\begin{tabular}{lcc}
\hline & Min-Max (TL) & Median (TL) \\
\hline Direct cost & $525-35326$ & 8668.50 \\
Acute care & $0-28521$ & 4752 \\
Rehabilitation & $0-15600$ & 625 \\
Medicine & $0-2102$ & 689 \\
Braces & $0-800$ & 0 \\
Botulinum neurotoxin & $0-2800$ & 0 \\
Visits & $60-2370$ & 865 \\
Indirect cost & $0-48000$ & 10800 \\
Total cost & $525-66560$ & 17253.50 \\
\hline
\end{tabular}

Min: Minimum; Max: Maximum; TL: Turkish Lira. 
Table 3. Assessment of the relationship between total cost and variables

\begin{tabular}{|c|c|c|c|}
\hline & \multicolumn{2}{|c|}{ Total cost (Turkish lira) } & \multirow[b]{2}{*}{$p$} \\
\hline & Mean \pm SD & Median & \\
\hline Sex & & & 0.202 \\
\hline Male & $21463,5 \pm 14115,8$ & 21122 & \\
\hline Female & $17367,9 \pm 10989,5$ & 14840 & \\
\hline Type of stroke & & & 0.334 \\
\hline Ischemic & $19536,1 \pm 13163,97$ & 16834,50 & \\
\hline Hemorrhagic & $23029,8 \pm 13143,7$ & 24043,50 & \\
\hline Spasticity & & & $0.028^{\star}$ \\
\hline No & $15672 \pm 10717,9$ & 14682,50 & \\
\hline Yes & $22585,8 \pm 13865,3$ & 21585 & \\
\hline Aphasia & & & 0.853 \\
\hline No & $20261,5 \pm 13521,4$ & 17920 & \\
\hline Yes & $19558,8 \pm 12793,5$ & 16691 & \\
\hline Depression & & & 0.186 \\
\hline No & $18701,1 \pm 11749,3$ & 16834,50 & \\
\hline Yes & $25268,3 \pm 17329,7$ & 235137 & \\
\hline Epilepsy & & & $0.037^{\star}$ \\
\hline No & $18958 \pm 12969,7$ & 16715 & \\
\hline Yes & $28235,2 \pm 12109,4$ & 25572 & \\
\hline BoNT & & & $0.001^{* *}$ \\
\hline No & $17624,3 \pm 11477,8$ & 15983 & \\
\hline Yes & $37176,9 \pm 12145,6$ & 34811 & \\
\hline Rehabilitation & & & $0.001^{* *}$ \\
\hline No & $12912,7 \pm 9240,7$ & 12398 & \\
\hline Yes & $26663,9 \pm 12843,5$ & 24814 & \\
\hline
\end{tabular}

SD: Standard deviation; ${ }^{\star} \mathrm{p}<0.05 ;{ }^{* *} \mathrm{p}<0.01$; Mann-Whitney U test.

depends on the quality and accuracy of the data used. This might induce some bias which is checked by sensitivity analyses. A review of studies conducted between 1966 and 2003 reported that sensitivity analyses were performed in less than one-third of the studies. Studies using data collected with bottom-up approach provide a more realistic picture of the costs. ${ }^{[15]}$ As in our study, a subpopulation analysis may be conducted using this approach and its results may be extrapolated to the general population. ${ }^{[4]}$

In the first year after a stroke, a considerable portion ( $76 \%$ on average) of stroke costs are devoted to inpatient treatment. However, a shift occurs in the following years with increased outpatient treatment and long-term care costs. ${ }^{[4]}$ In some countries, stroke patients stay in inpatient treatment facilities for only a short period. ${ }^{[16]}$ In most European countries, particularly in Netherlands and Scotland, a smaller part of the total cost is spent on outpatient treatment (3\% and $2 \%$ respectively) as opposed to North American countries (United States and Canada). Countries that spend a relatively large part on long-term care, spent a relatively small portion on inpatient care. This might be explained by variations in the organization of care in these countries. For instance, in some countries, rehabilitation and nursing home care is part of the inpatient hospital organization, whereas in other countries these are separate facilities. ${ }^{[4]}$

Average annual costs of stroke range from $\$ 7,342$ to $\$ 146,149$ in many countries. ${ }^{[17]}$ In a study conducted in Sweden with 140 stroke survivors who were followed for one year, estimated average cost per patient was $\$ 32,976$. Hospitalization costs accounted for the majority of the total cost. In the present study, average total cost was 19,951.99 TL (8,674.77 USD). Costs of acute inpatient care represented the largest part of the direct costs for our patients. Interventions increasing the total cost such as thrombolysis and endovascular surgeries are not often performed in acute care facilities. In our study, direct costs were slightly greater than indirect costs. Currently, the retirement age is 65 in Turkey; estimated indirect costs were low since most of our study population were over the age of 65 years. If in our study population were younger, employed persons, indirect costs and accordingly total costs would have been much higher. The duration of hospitalization was identified as a factor that significantly increased the total cost.

Cost of informal care (cost of caregiver and caregiver's loss of productivity), a component of indirect costs, constitutes a major part of the total cost of care. ${ }^{[13]}$ Caregiver burden was not calculated in the present study. Considering the chronic nature of stroke, it would obviously increase the cost of long-term care. In a cost analysis conducted by Saka et al ${ }^{[3]}$ it was found that $50 \%$ of total costs were spent on patient care, $27 \%$ accounting for direct costs and $24 \%$ for indirect costs incurred by the patient's loss of productivity. In a Korean study, ${ }^{[18]}$ indirect costs were identified as the largest component of the overall cost and an Irish study ${ }^{[19]}$ found that the largest part of the total cost was spent during the chronic phase of the illness due to high indirect cost and cost of nursing home care. The total omission of informal care costs in the majority of the COI studies is noteworthy. ${ }^{[4]}$ In several studies, only out-of-pocket caregiver's costs and not informal care time. ${ }^{[16]}$ In our study, neither the informal care time nor the expenses of caregivers were analyzed as part of cost analysis.

A negative correlation was found between the total cost of stroke and age of the patient. Since elderly stroke survivors are sometimes neglected by their families and often suffer from cognitive impairment and do not receive rehabilitation services, advanced age can be considered as a factor that reduces the cost of stroke. On the other hand, younger stroke patients generally participate in rehabilitation programs and receive more support during long-term treatment. Our results show 
that aphasia and depression do not have an impact on the cost of stroke. In Turkey, most of the stroke patients do not receive aphasia treatment because of the small number of speech physiotherapists. Studies have shown that psychiatric comorbidity caused by stroke is generally not taken into account. ${ }^{[20]}$

The cost of stroke was significantly higher among patients with spasticity. Direct costs for 12-month stroke survivors were four times higher than direct costs for patients with stroke without spasticity as reported by Lundström et al. ${ }^{[15]}$

One limitation of our study was the exclusive enrollment of patients who were still alive one year after stroke. The cost for patients who died after a stroke was not included in the analysis. Another limitation of our study is that it was a small scale study which did not involve patients from other parts of Turkey. Also, caregiving cost incurred by productivity loss and informal care time were not taken into account because caregivers were mostly patients' relatives.

The cost of stroke will increase even further in the future with the overall aging of the world's population. In an Irish study conducted in 2007, future costs of stroke in Ireland were estimated to increase by $50 \%$ between 2007 and 2021. ${ }^{[19]}$ Cerebrovascular diseases alone account for $5.9 \%$ of the total disease burden in Turkey according to DALY estimations, indicating that stroke is a priority public health concern. ${ }^{[5]}$

Further studies in a larger number of patients are needed to estimate the cost of stroke in Turkey using national statistics taking into account regional differences in costs and data obtained should be used to guide healthcare expenditures. This will help reduce mortality and disability associated with stroke through planning a more effective allocation of resources and developing both chronic and acute care strategies for stroke management.

\section{Declaration of conflicting interests}

The authors declared no conflicts of interest with respect to the authorship and/or publication of this article.

\section{Funding}

The authors received no financial support for the research and/or authorship of this article.

\section{REFERENCES}

1. Murray CJ, Lopez AD. Global mortality, disability, and the contribution of risk factors: Global Burden of Disease Study. Lancet 1997;349:1436-42.

2. di Carlo A. Human and economic burden of stroke. Age and Aging 2009;38:4-5.

3. Saka O, McGuire A, Wolfe C. Cost of stroke in the United
Kingdom. Age Ageing 2009;38:27-32.

4. Evers SMAA, Struijts JN, Ament AJHA, Genugten MLL, Jager CJ, Boss GAM. Comments, opinions and reviews: International comparison of stroke cost studies. Stroke 2004;35:1209-15.

5. Türkiye Hastalık Yükü Çalışması 2004. In: Ünivar N, Mollahaliloğlu S, Yardım N, editors. Ankara 2006. RSHMB Hıfzısıhha Mektebi Müdürlüğü, Sağlık Bakanlığı, Aydoğdu Ofset Matbaacilık; 2007. s. 42-51.

6. Abakcı G, Abacı A, Ertaş FS, Özerkan F, Erol Ç, Oto A. Türkiye' de hipertansif hastalarda inme riski ve inme riski açısından bölgesel farklılıkların belirlenmesi: Hastane tabanlı, kesitsel, epidemiyolojik anket (THINK) çalışması. Türk Kardiyol Dern Arş 2006;34:395-405

7. Brown RD, Whisnant JP, Sicks JD, O'Fallon WM, Wiebers DO. Stroke incidence, prevalence, and survival: secular trends in Rochester, Minnesota, through 1989. Stroke 1996;27:373-80.

8. Selçuk B, Kumbara F, Kurtaran A, Ersöz M, Akyüz M. Cost analysis of patients with stroke during their stay in a rehabilitation center. Fiziksel Tip 2005;8:95-101.

9. Available from: https://www.sgk.gov.tr/wps/portal/tr/ mevzuat/yururlukteki_mevzuat/tebligler/

10. Ommaty R. Vital ilaç rehberi. İstanbul: Pelikan Tip ve Teknik Kitapçılık; 2014.

11. Ghatnekar O, Persson U, Glader EL, Terént A. Cost of stroke in Sweden: an incidence estimate. Int J Technol Assess Health Care 2004;20:375-80.

12. Kolominsky-Rabas PL, Heuschmann PU, Marschall D, Emmert M, Baltzer N, Neundörfer B, et al. Lifetime cost of ischemic stroke in Germany: results and national projections from a population-based stroke registry: the Erlangen Stroke Project. Stroke 2006;37:1179-83.

13. Youman P, Wilson K, Harraf F, Kalra L. Youman P, Wilson K, Harraf F, Kalra L. Pharmacoeconomics 2003;21:43-50.

14. Dewey HM, Thrift AG, Mihalopoulos C, Carter R, Macdonell RA, McNeil JJ, et al. Lifetime cost of stroke subtypes in Australia: findings from the North East Melbourne Stroke Incidence Study (NEMESIS). Stroke 2003;34:2502-7.

15. Lundström E, Smits A, Borg J, Terént A. Four-fold increase in direct costs of stroke survivors with spasticity compared with stroke survivors without spasticity: the first year after the event. Stroke 2010;41:319-24.

16. Moon L. Stroke treatment and care: a comparison of approaches in OECD countries. In: Organization for Economic Cooperation and Development (OECD). A Disease-Based Comparison of Health Systems. Paris: Organization for Economic Cooperation and Development OECD; 2003.

17. Luengo-Fernandez R, Gray AM, Rothwell PM. Costs of stroke using patient-level data: a critical review of the literature. Stroke 2009;40:18-23.

18. Lim SJ, Kim HJ, Nam CM, Chang HS, Jang YH, Kim S, et al. Socioeconomic costs of stroke in Korea: estimated from the Korea national health insurance claims database. J Prev Med Public Health 2009;42:251-60. [Abstract]

19. Smith S, Horgan F, Sexton E, Cowman S, Hickey A, Kelly P, et al. The future cost of stroke in Ireland: an analysis of the potential impact of demographic change and implementation of evidence-based therapies. Age Ageing 2013;42:299-306.

20. Evers SMAA, Ament AJHA, Driesen GAM. The use of mental health care by patients with cerebrovascular disease: a costanalysis. Int J Technol Assess Health Care 2002;18:33-45. 